\title{
Layanan Bimbingan Kelompok untuk Meningkatkan Time Management Skill pada Siswa
}

\author{
Maryati \\ SMA N 1 Sungai Penuh
}

Article Info:

Accepted 8Juli 2019

Published Online 27 Juli 2019

\begin{abstract}
Abtract
Every human being has the same time in a 24-hour day, as well as high school students who have extraordinary activities. Managing an effective time is not an easy task. The many problems of managing the time experienced by students both for learning, socializing and channeling hobbies make students feel time-chased. Through the Layanan Bimbingan Kelompok in the activity of guidance and counseling students participating in a group, counseling raised the problems they were dealing with relating to daily time management. Group Guidance Activities are carried out according to stages. The predetermined stage is the formation stage, the transitional stage, and the Activity Phase and the Termination Phase. In the Guidance Service, the Group carries out two cycles where in the first cycle participants express and find solutions to their problems daily in problems that relate to time. Based on the results of the first cycle it turns out students experience a lack of time to act. In the second cycle, students are given an explanation of how to manage daily time effectively and efficiently, from observations and student reports it turns out students experience positive changes in time management so that participants in the Group Guidance Service are overcome the problems he experienced so far.
\end{abstract}

Keywords: layanan bimbingan kelompok, time management skill distribution, and reproduction in any medium, provided the original work is properly cited. C2019 by author

\section{PENDAHULUAN}

Keberhasilan dalam pendidikan tidak hanya dinilai dari berhasil atau tidaknya mengantar peserta didik mendapat angka akademiknya yang tinggi melainkan untuk dapat mengantar peserta didik memililki kepribadian yang utuh dan karakter yang baik (Ifdil, 2010), hal ini merupakan tanggung jawab semua pendidik termasuk guru Bimbingan dan Konseling.

Berdasarkan hasil pengamatan dan laporan dari orang tua siswa serta menggunakan angket kebutuhan peserta didik, ditemukan sebagian besar siswa mengalami kesulitan dalam mengatur waktu sehari -hari, hal ini akan berdampak terhadap kegiatan belajar siswa. Menyikapi masalah tersebut perlu kiranya diberi suatu layanan kepada siswa, salah satu layanan yang dianggap tepat adalah layanan bimbingan kelompok. Layanan dengan pendekatan kelompok dapat memberi kesempatan pada masing-masing anggota kelompok untuk mendapatkan informasi, memberi tanggapan dan reaksi timbal balik dalam menyelesaikan masalah. Adapun tahap-tahap yang dilalui berdasarkan prosedur dalam bimbingan kelompok. Dalam kegiatan layanan Bimbingan kelompok sering ditemui adanya suasana diam. Dikarenakan peserta kelompok mengalami kesulitan dalam mengungkapkan permasalahannya karena mengalami kesulitan dalam berbicara atau karena belum merasa akrab dengan peserta lainnya. Masalah ini harus diatasi dengan menggunakan berbagai permainan dengan tujuan menumbuhkan keakraban antar peserta kelompok. 
Prayito (1995:178) mengemukakkan bahwa Bimbingan Kelompok adalah suatu kegiatan yang dilakukan oleh sekolompok orang dengan memanfaatkan dinamika untuk mencapai tujuan tujuan bimbingan dan konseling. Bimbingan kelompok lebih menekankan suatu upaya bimbingan kepada individu melalui kelompok. Kemudian Sukardi (2002: 48) menjelaskan bahwa bimbingan kelompok adalah layanan yang memungkin sejumlah peserta didik secara bersama -sama memperoleh bahan dari nara sumber tertentu (terutama guru pembimbing atau Konselor) yang berguna untuk menunjang kehidupan sehari-hari baik individu sebagai pelajar, anggota keuarga, dan masyarakat serta untuk mempertimbangkan dalam pengambilan keputusan.

Dengan demikian dapat disimpulkan bimbingan kelompok adalah proses pemberian informasi dan bantuan yang diberikan oleh sesorang yang ahli (Guru Pembimbing) pada sekelompok orang dengan memanfaatkan dinamika kelompok guna mncapaisuatu tujuan tertentu,tujuan dalam penelitian tindakan kelas ini adalah mengatur waktu.

Bimbingan kelompok pada umumnya dilakukan melalui empat tahap, yaitu (1) tahap pembentukan, tahap Pembentukan merupakan tahap pengenalan, tahap pelibatan diri, tahap memasukan diri kedalam kehidupan suatu kelompok. Pada tahap ini para anggota saling memperkenalkan diri dan mengungkapkan tujuan atau harapan-harapan yang ingin dicapai. Tujuan dari tahapan ini adalah agar tumbuh suasana kelompok, tumbuhnya minat anggota mengikuti kegiatan kelompok, tumbuh suasana saling mengenal,percaya, menerima, dan membantu diantara anggota kelompok; (2) tahap peralihan, setelah tahap pembentukan Bimbingan kelompok dapat dilanjutkan ketahap berikutnya yaitu tahap peralihan, dimana tahap ini merupakan pembangunan jembatan antara tahap pertama dan tahap ketiga; (3) tahap kegiatan, tahap ketiga dari Bimbingan kelompok adalah tahap pelaksanaan kegiatan atau tahap kegiatan pencapaian tujuan, tahap ini merupakan tahap yang sebenarnya dari bimbingan kelompok, namum kelangsungan kegiatan kelompok pada tahap ini amat tergantung dari keberhasilan dua tahap sebelumnya; (4) tahap pengakhiran, tahap keempat dari bimbingan kelompok adalah tahap pengakhiran atau tahap penilaian dan tindak lanjut, pada tahap ini kegiatan Bimbingan kelompok hendaknya dipusatkan pada pembahasan dan penjelajahan tentang apakah para anggota akan mampu menerapkan hal-hal yang telah mereka bahas dalam bimbingan kelompok (Prayitno, 1995: 40).

Menurut Kamus Besar Bahasa Indonesia (1997) waktu adalah seluruh rangkaian saat ketika proses, perbuatan, atau keadaan berada atau berlangsung. Pengaturan waktu atau manajemen waktu (time management) adalah suatu perencanaan, mengorganisir, menggerakkan, dan pengawasan, terhadap produktivitas waktu. Pengertian manajemen waktu dapat juga diartikan sebagai suatu metode atau cara untuk memanfaatkan dan mengatur setiap bagian waktu dalam mengerjakan aktivitas yang sudah direncanakan dan harus diselesaikan dalam jangka waktu yang sudah ditetapkan.

\section{METODE}

Penelitian ini dilakukan di SMA N I Sungai Penuh. Penelitian dilakukan selama 4 bulan yaitu dari bulan Juli sampai dengan bulan Desember 2018. Subyek penelitian adalah siswa kelas X IPA I tahun pelajaran 2018 yang berjumlah 35 siswa yang hadir 31 siswa dengan 11 siswa laki-laki dan 20 siswa perempuan. Dalam penelitian ini menggunakan pendekatan Penelitian Tindakan Kelas, yang terdiri dari 2 siklus atau lebih dan masing-masing siklus terdiri dari 4 kegiatan utama yaitu: planning (perencanaan), action (tindakan), observation (observasi), Reflection Refleksi.

Adapun alur kerja penelitian tindakan kelas menurut Kemmis dan Mc. Taggart dalam Zainal Akib (2004: 6) dapat di gambarkan dalam bagan 1 sebagai berikut:

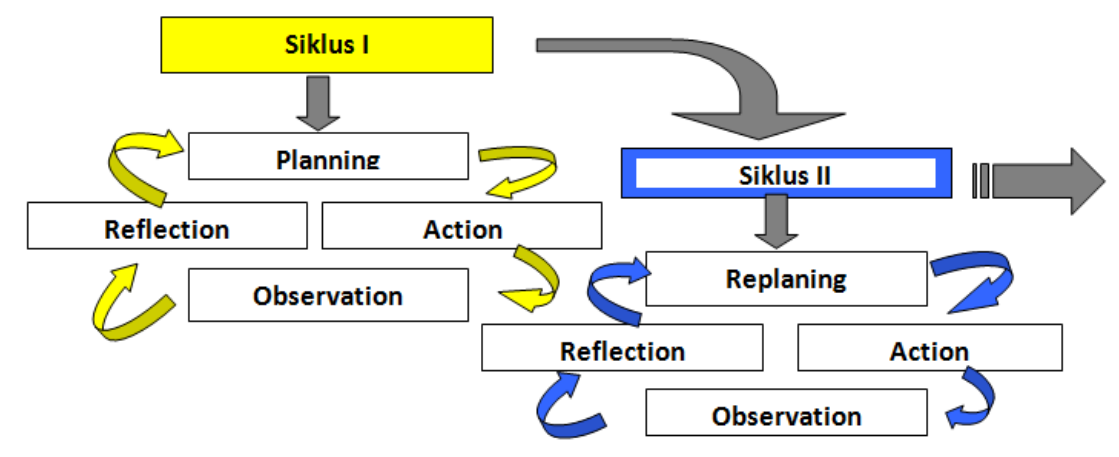


Bagan 1. Alur kerja penelitian tindakan kelas

Dalam penelitian ini Teknik atau metode yang digunakan adalah : Observasi, wawancara konseling, pemberian tugas, kuesioner (angket). Teknik analisis data dilakukan seperti yang digambarkan pada bagan 2.

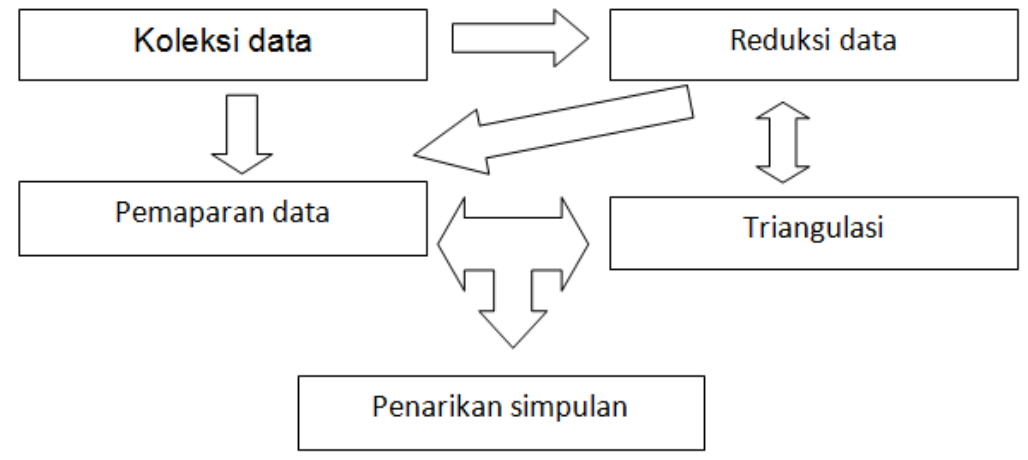

Bagan 2. Teknik analisis data

Adapun indikator keberhasilan penelitian ini adalah: 1) Peserta didik dapat mengungkapkan masalahnya secara sukarela melalui Layanan Bimbingan Kelompok; 2) Peserta didik dapat mengurangai tekanan psikologisnya melalui kegiatan permainan-permainan dalam layanan Bimbingan Kelompok; 3) Peserta didik melalui layanan Bimbingan Kelompok dapat mengatur waktu dengan efektif dan efisien.

\section{HASIL PENELITIAN}

\section{Deskripsi Kondisi Awal}

Sebelum Penelitian di mulai peneliti melakukan pendataan masalah atau kebutuhan siswa dalam pelaksanaan Layanan Bimbingan dan Konseling melalui angket Kebutuhan Peserta Didik Hasil analisa angket ini menjadi dasar guru Pembimbing memberi layanan kepada siswa yang dibinannya.Angket ini memiliki 50 item kebutuhan siswa. Dimanaa dari instrument ini dapat disimpulkan jika jumlah responden pada item mencapai 1-10\% item maka kelas tersebut tidak ada masalah, $11-20 \%$ kelas tersebut agak bermasalah, persentase $21-$ $36 \%$ kelas tersebut cukup bermasalah, persentase $37-50$ tersebut bermasalah dan perlu adanya layanan BK dan persentase $51-100 \%$ kelas tersebut sangat bermasalah dan perlu adanya layanan BK. Hasil assesment terhadap 35 siswa ditemukan 8 siswa dengan persentase lebih dari $50 \%$, sehingga ke 8 siswa tersebut perlu mendapatkan layanan bimbingan kelompok. Dalam praktrik Bimbingan kelompok perlu diikutkan siswa yang tidak bermasalah sebagai teman berbagi, untuk itu dalam kegiatan ini di tambah 1 siswa lagi yaitu ketua kelas atau teman yang disenangi di kelas tersebut. Selanjutnya hasil assesment terhadap siswa dapat dilihat pada tabel berikut:

Tabel 1 : Hasil Angket Kebutuhan Siswa

\begin{tabular}{clll}
\hline No & \multicolumn{1}{c}{ Kode Siswa } & \multicolumn{1}{c}{ Persentase } & \multicolumn{1}{c}{ Keterangan } \\
\hline $\mathbf{1}$ & MR 26 2018 & $52 \%$ & Peserta Bimbingan Kelompok \\
$\mathbf{2}$ & MR02 2018 & $70 \%$ & Peserta Bimbingan Kelopok \\
$\mathbf{3}$ & MR19 2018 & $15 \%$ & Partisipan \\
$\mathbf{4}$ & MR24 2018 & $60 \%$ & Peserta BimbinganKelompok \\
$\mathbf{5}$ & MR 20 2018 & $65 \%$ & Peserta Bimbingan Kelompok \\
$\mathbf{6}$ & MR 33 2018 & $60 \%$ & Peserta Bimbingan Kelompok \\
$\mathbf{7}$ & MR 07 2018 & $62 \%$ & Peserta Bimbingan Kelompok \\
$\mathbf{8}$ & MR 27 2018 & $54 \%$ & PesertaBimbingan Kelompok \\
$\mathbf{9}$ & MR 29 2018 & $62 \%$ & Peserta Bimbingan Kelompok \\
$\mathbf{1 0}$ & MR 08 2018 & \multicolumn{1}{c}{$10 \%$} & Partisipan \\
\hline
\end{tabular}




\section{Dekripsi Hasil Siklus I}

Berdasarkan hasil assement selanjutnya konselor melakukan penelitian tindakan kelas, yang hasilnya dapat di lapokan sebagai berikut: 1) Perencanaa (menyiapkan angket kebutuhan peserta didik, menjelaskan kegunaan angket dan cara mengisinya, menganalisa hasil angket, menyiapkan lembar observasi menyiapkan lembar evaluasi); 2) Pelaksanaan (melakukan tahap pembentukan Bimbingan kelompok dengan diawali doa dan menyampaikan maksud dan tujuan kegiatan bimbingan kelompok.kemudian melaksanakan permainan rangkaian nama dan kebun binatang, dengan tujuan membentuk dinamika kelompok sehingga antar anggota kelompok saling mengenal, akrab, hangat nyaman satu sama lain, memberi kesempatan kepada siswa untuk mengemukan masalah yang dialaminya yang berhubungan dengan waktu, peserta bimbingan kelompok mengemukan pendapat atau saran seerhana kepada peserta yang bermasalah)

Tabel 2 : Bimbingan Kelompok Siklus 1

\begin{tabular}{|c|c|c|}
\hline \multirow{2}{*}{$\frac{\text { Kode Siswa }}{\text { MR } 2620181}$} & Masalah & Pemecahan Masalah \\
\hline & $\begin{array}{l}\text { Sering terlambat pulang karena } \\
\text { mengikuti kegiatan ekstra lebih } \\
\text { dari satu }\end{array}$ & $\begin{array}{l}\text { 1) Berusaha memilih salah satu saja } \\
\text { 2) Memberi tahu kepada orang tua kalau ada } \\
\text { acara }\end{array}$ \\
\hline MR 0220182 & $\begin{array}{l}\text { Sering tidak masuk sekolah karena } \\
\text { bekerja jadi buruh haría } \\
\text { mencukupi biaya jajan }\end{array}$ & $\begin{array}{l}\text { 1) Berhemat dan biasakan sarapan dirmah } \\
\text { 2) Bekerja diluar jam sekolah atau hari libur }\end{array}$ \\
\hline MR19 20183 & $\begin{array}{l}\text { Partisipasi dalam memecahkan } \\
\text { masalah }\end{array}$ & \\
\hline Mr 242018 & $\begin{array}{l}\text { Sering tidak buat PR karena } \\
\text { banyak menggunakan Game }\end{array}$ & $\begin{array}{l}\text { 1) Memanfaatkan Hand fhone untuk yang } \\
\text { penting saja } \\
\text { 2) Matikan hand pone saat belajar }\end{array}$ \\
\hline MR 2020185 & $\begin{array}{l}\text { Sering tidak bisa mengikuti acara } \\
\text { keluarga karena banyak PR }\end{array}$ & $\begin{array}{l}\text { 1) Mengerjakan PR setelah pulang sekolah } \\
\text { 2) Membuat rencana lebih awal }\end{array}$ \\
\hline MR 3320186 & $\begin{array}{l}\text { Sering diajak kawan SMP main } \\
\text { pulang sekolah }\end{array}$ & $\begin{array}{l}\text { 1) Menolak ajakan dengan baik } \\
\text { 2) Memberi alasan yang tepat }\end{array}$ \\
\hline MR 1620187 & $\begin{array}{l}\text { Sering telat karena jemput dan } \\
\text { antar pacar }\end{array}$ & $\begin{array}{l}\text { 1) Membuat jarak dengan pacar } \\
\text { 2) Menenmkan nilai-nilai agama }\end{array}$ \\
\hline MR 2720188 & $\begin{array}{l}\text { Punya tugas cuci piring } \\
\text { dirumah,sehingga terlambat } \\
\text { kesekolah }\end{array}$ & $\begin{array}{l}\text { 1) Berusaha semua anggota rumah bangun } \\
\text { lebih awal } \\
\text { 2) Mandi dulu baru sarapan }\end{array}$ \\
\hline MR 2920189 & $\begin{array}{l}\text { Banyak mengikuti les privat } \\
\text { sehingga merasa kekurangan } \\
\text { waktu untuk istirahat } \\
\text { Partisipan }\end{array}$ & $\begin{array}{l}\text { 1). Menentukan mata pelajaran yang } \\
\text { Sulit dipahami } \\
\text { 2)berusaha belajar sendiri }\end{array}$ \\
\hline
\end{tabular}

Selanjutnya setelah Bimbingan kelompok pada siklus 1 selesai maka konselor/peneliti mengadakan evaluasi, terhadap aspek afektif, kognitif dan psikomotorik siswa dengan lembar evaluasi. Setelah kegiatan evaluasi konselor melakukan kegiatan tindak lanjut, sebagai berikut: 1) memberikan kegiatan curah pendapat, peserta kelompok tentang kegiatan; 2) memberikan penguatan kepada peserta kelompok yang berhasil; 3) memonitor (melakukan penilaian jangka pendek) pelaksanaan hasil keputusan Bimbingan kelompok siklus I dengan lembar monitoring.

\section{Deskripsi Hasil Siklus II}

Berdasarkan hasil observasi, monitoring, analisis dan refleksi pada siklus I selanjutnya konselor melakukan tindakan pada siklus II, yang hasilnya dapat dilaporkan sebagai berikut: 1) Perencanaan (membuat kesepakatan dan komitmen dengan konseli, menentukan jadwal bimbingan kelompok dan kegiatan pendukungnya, menyiapkan materi mengenai pengaturan waktu yang sfektif dan efisien, menyiapkan lembar observasi, menyiapkan lembar evaluasi, menyiapkan permainan dalam kelompok); 2) Pelaksanaan (melakukan permainan bimbingan kelompok anak kembar dan mengapa, karena pembimbing memberi penjelasan tentang mengatur waktu yang efektif dan efien, materi ringkas pengaturan waktu). 
Tabel 3 :Hasil Bimbingan kelompok siklus II

\begin{tabular}{|c|c|c|}
\hline Kode Siswa & Masalah & Pemecahan Masalah \\
\hline MR 262018 & $\begin{array}{l}\text { Masih sering terlambat dan orang } \\
\text { tua sering marah }\end{array}$ & $\begin{array}{l}\text { Siswa memutuskan untuk memilih satu saja } \\
\text { ekskul. Mediasi dengan orang tua agar } \\
\text { memahami kegiatan siswa }\end{array}$ \\
\hline MR 022018 & $\begin{array}{l}\text { Masih sering tidak hadir karena } \\
\text { bekerja sebagai buruh guna } \\
\text { memenuhi uang jajan dan bantú } \\
\text { ekonomi keluarga }\end{array}$ & $\begin{array}{l}\text { Siswa sudah mulai datang tepat waktu tapi masih } \\
\text { ada juga alpa. Tindakan selanjutnya pembimbing } \\
\text { akan mengadakan pertemuan dengan orang tua }\end{array}$ \\
\hline MR19 2018 & $\begin{array}{l}\text { Partisipasi dalam memecahkan } \\
\text { masalah }\end{array}$ & \\
\hline MR25 2018 & $\begin{array}{l}\text { Masih sering tidak buat pekerjaan } \\
\text { rumah karena main Game }\end{array}$ & $\begin{array}{l}\text { Mengurangi pergi ke warnet karena bisa } \\
\text { mengganggu belajar }\end{array}$ \\
\hline MR20 2018 & $\begin{array}{l}\text { Masih sering tidak mengikuti acara } \\
\text { keluarga karena banyak PR }\end{array}$ & $\begin{array}{l}\text { 1) Membuat janji terlebih dahulu dengan } \\
\text { keluarga agar bisa mengerjakan PR lebih awal } \\
\text { 2) Memberi pemahaman dengan keluarga bahwa } \\
\text { tidak semua acara diikutu karena memnag } \\
\text { banyak tugas } \\
\text { 3) Mengalih acara pada hari Minggu atau hari } \\
\text { libur }\end{array}$ \\
\hline MR 332019 & $\begin{array}{l}\text { Masih terlambat pulang karena } \\
\text { diajak teman akrab }\end{array}$ & $\begin{array}{l}\text { 1. Memberi pengertian dengan teman akrab } \\
\text { dampak terlambat pulang banyak tugas yang } \\
\text { tidak dikerjakan serta sering membuat orang } \\
\text { tu acemas } \\
\text { 2. Mediasi drngan teman siswa untuk mengatur } \\
\text { waktu bermain dan kegiatan lainnya }\end{array}$ \\
\hline MR 162018 & $\begin{array}{l}\text { Sudah tidak berhubungan akrab } \\
\text { dengan pacar .dilarang membawa } \\
\text { motor kesekolah oeh orang tua }\end{array}$ & $\begin{array}{l}\text { Mengadakan mediasi dengan orang tua untuk } \\
\text { memberi izin lagi memakai motor karena jarak } \\
\text { rumah kesekolah cuckup jauh }\end{array}$ \\
\hline MR27 2018 & Tidak terlambat lagi & $\begin{array}{l}\text { 1. Mediasi dengan orang tua, orang tua bersama } \\
\text { memperhatikan anak dan tidak memberi tugas } \\
\text { padapagi hari } \\
\text { 2. Sekeluarga bangun lebih awal }\end{array}$ \\
\hline MR 292018 & Masih mengikuti les privat & $\begin{array}{l}\text { 1) Menyarankan siswa bersabar } \\
\text { 2) Menetukan sikap sesuai saran teman } \\
\text { 3) Bisa belajar lewat ruang guru di Internet }\end{array}$ \\
\hline MR 082018 & Partisipan & . \\
\hline
\end{tabular}

Selanjutnya setelah Bimbingan kelompok pada siklus II selesai maka konselor/peneliti mengadakan evaluasi, terhadap aspek afektif, kognitif dan psikomotorik siswa dengan lembar evaluasi.

\section{PEMBAHASAN}

\section{Pengumpulan Data (Data Collection) dan Reduksi Data}

Setelah dilakukan tindakan siklus I dan siklus II , dan masing-masing siklus telah dilakukan observasi, monitoring dan evaluasi, maka dari hasil evaluasi aspek afektif, kognitif dan psikomotorik diperoleh data sebagai berikut : 
Tabel 4 : Reduksi data hasil evaluasi siswa

\begin{tabular}{|c|c|c|c|c|c|c|c|}
\hline No & Pernyataan & & Siklus I & & & Siklus Ii & \\
\hline a. & Afektif (perasaan positif) & Setuju & $\begin{array}{c}\text { Tidak } \\
\text { Setuju }\end{array}$ & $\%$ & Setuju & $\begin{array}{c}\text { Tidak } \\
\text { Setuju }\end{array}$ & $\%$ \\
\hline 1) & $\begin{array}{l}\text { Melalui Angket Kebutuhan } \\
\text { Peserta didik saya lebih mudah } \\
\text { mengungkapkan masalah saya }\end{array}$ & 10 & - & $100 \%$ & 10 & - & $100 \%$ \\
\hline 2) & $\begin{array}{l}\text { Kegiatan permainan dalam } \\
\text { bimbingan kelompok membuat } \\
\text { saya merasa senang, segar dan } \\
\text { merasa terbebas dari tekanan }\end{array}$ & 10 & - & $100 \%$ & 10 & & $100 \%$ \\
\hline 3) & $\begin{array}{l}\text { Melalui layanan Bimbingan } \\
\text { kelompok saya merasa nyaman } \\
\text { karena bisa berbagi masalah, } \\
\text { perasaan, pendapat dengan } \\
\text { anggota kelompok. }\end{array}$ & 10 & - & $100 \%$ & 10 & & $100 \%$ \\
\hline b. & Kognitif (pemahaman baru) & Setuju & $\begin{array}{l}\text { Tidak } \\
\text { Setuiu }\end{array}$ & $\%$ & Setuju & $\begin{array}{l}\text { Tidak } \\
\text { Setuiu }\end{array}$ & $\%$ \\
\hline 1) & $\begin{array}{l}\text { Angket Kebutuhan Peserta Didik } \\
\text { salah satu alat untuk membantu } \\
\text { memudahkanSiswa dalam } \\
\text { mengungkap masalah }\end{array}$ & 10 & - & $100 \%$ & 10 & - & $100 \%$ \\
\hline 2) & $\begin{array}{l}\text { Permainan dalam kegiatan } \\
\text { Bimbingan Kelompok adalah } \\
\text { suatu permainan yang punya } \\
\text { fungsi untuk terapi atau untuk } \\
\text { mengurangi ketegangan, } \\
\text { mengurangi beban pikiran dan } \\
\text { untuk membentuk kondisi } \\
\text { kelompok yang dinamis. }\end{array}$ & 10 & - & $100 \%$ & 10 & - & $100 \%$ \\
\hline 3) & $\begin{array}{l}\text { Layanan Bimbingan Kelompok } \\
\text { adalah layanan yang memberikan } \\
\text { kesempatan pada tiap in } \\
\text { dividualah individu dalam } \\
\text { suasana kelompok, agar } \\
\text { terpecahkan masalahnya }\end{array}$ & 10 & - & $100 \%$ & 10 & - & $100 \%$ \\
\hline c. & Psikomotorik (unjuk kerja) & Ya & Tidak & $\%$ & Ya & Tidak & $\%$ \\
\hline 1) & $\begin{array}{l}\text { Menjawab isi angket sesuai } \\
\text { kebutuhan }\end{array}$ & 10 & - & $100 \%$ & 10 & - & $100 \%$ \\
\hline 2) & $\begin{array}{l}\text { Mengikuti semua kegoatan } \\
\text { permainan kelompok }\end{array}$ & 10 & - & $70 \%$ & 10 & - & $100 \%$ \\
\hline 3) & $\begin{array}{l}\text { Mengikuti kegiatan layanan } \\
\text { Bimbinan kelompok dari awal } \\
\text { sampai akhir }\end{array}$ & 10 & - & $60 \%$ & 10 & - & $100 \%$ \\
\hline 4) & $\begin{array}{l}\text { Menyampaikan pendapat secara } \\
\text { lisan, memberikan usul dan } \\
\text { berkomunikasi lisan dengan } \\
\text { konselor dan seluruh anggota } \\
\text { kelompok }\end{array}$ & 8 & 2 & $80 \%$ & 10 & - & $100 \%$ \\
\hline 5) & $\begin{array}{l}\text { Membuat rencana kegiatan } \\
\text { untuk menyelesaikan masalah }\end{array}$ & 9 & $1-$ & $90 \%$ & $\mathbf{1 0}$ & - & $100 \%$ \\
\hline
\end{tabular}




\section{Pemaparan Data}

Untuk keabsahan data dalam penelitian ,Pneliti menggunakan tiga sumber yang dipercaya yakni Perserta atau konseli kelompok yng bermasalah peneliti sendiri, dan bantuan pengamatan dari wali kelas .Berdasarkan hasil data diatas sudah di kemukakan diatas. dapat dipaparkan hal-hal sebagai berikut: 1) dari aspek afektif, pada siklus I maupun siklus II menunjukan bahwa siswa (konseli) memiliki perasaan yang positif yang diwujudkan dalam perasaan senang mengikuti kegiatan permaianan dalam Layanan Bimbingan kelompok. Dan mengungkapkan masalah melalui angket kebutuhan peserta didik; 2) dari aspek kognitif pada siklus I maupun siklus II, menunjukan bahwa siswa (konseli) memiliki pemahaman baru manfaat Bimbingan kelompok dalam mengatasi masalah mereka dalam mengatur waktu efektif dan efisien; 3) dari aspek psikomotorik pada siklus I masih di temukan siswa yang kurang aktif atau tidak tidak memberikan tanggapan dan solusi, juga masih ditemukan siswa yang tidak menjalankan keputusan Bimbingan kelompok, sering terlambat di sekolah dan membolos sekolah, dan masal belum terselesaikan atau timbul masalah baru serta ada hubungan dengan orang tua yang belum terselesaikan. Sedangkan pada siklus II rancana kegiatan dan unjuk kerja siswa sudah berjalan baik dan masalah juga sudah terpecahkan serta hubungan dengan orang tua telah membaik.

\section{KESIMPULAN}

Dari langkah-langkah pengolahan data diatas dapat di simpulkan beberapa hal dari penelitian ini sebagai berikut: 1) Penggunaan angket Kebutuhan Peserta Didik bisa memudahkan siswa dalam mengungkapkan masalah sehingga konselor/peneliti juga lebih mudah dalam memahami masalah siswa; 2) Permainan dalam Bimbingan kelompok membantu menciptakan suasana rileks, menyenangkan, membantu anggota untuk saling mengakrabkan diri sehingga memperlancar pelaksanaan layanan Bimbingan kelompok; 3) Layanan Bimbingan kelompok membuat siswa mendapatkan pengalaman dalam berbagi, saling menghargai, salaing memberi tanggapan dan solusi dan menumbuhkan tekat untuk memecahkan masalah bersama sehingga masalah yang di alami masing-masing individu bisa dibahas dan dipecahkan dalam Layanan Bimbingan kelompok; 4) Melalui Layanan Bimbingan kelompok guru pembimbing lebih focus memberi materi pengaturan waktu yang efektif dan efisien.karena bermanfaat sekali bagi peserta bimbingan; 5) Melalui Layanan Bimbingan Kelompok siswa dapat mengatur waktu dengan efektif dan efesien tampa merasa terburu-buru dalamberaktivitas sehari-hari

\section{DAFTAR RUJUKAN}

Andori. (2017). Program Bimbingan dan Konseling Berdasarkan Panduan Operasional Penyelenggaraan BK (POP BK). Yogyakarta: Paramitra Publishing.

Axline, Virginia. (2009). Play Therapy. http://id.wikipedia.org/ wiki

Dinas pendidikan. (2006). Program Pengembangan Diri Bimbingan dan Konseling. Jakarta: Dikmenum

Dinas pendidikan. (2002). Panduan Pelayanan Bimbingan dan Konseling Berbasis Kompetensi . Jakarta: Dikmenum

Ifdil, I. (2010). Pendidikan Karakter dalam Bimbingan dan Konseling. Pedagogi: Jurnal Ilmu Pendidikan, $10(2), 55-61$.

Kartini, Kartono. (2003). Kamus Psikologi. Jakarta: Balai Pustaka

Malahayati. (2010). Super Teens. Yogyakarta: Percetakan Galangpress

Maxmanroe (2019). Manajemen Waktu: Pengertian, Manfaat, Serta Fungsi dan Tujuannya. Dikutip 6 Agustus 2019 dari Maxmanroe: https://www.maxmanroe.com/vid/manajemen/pengertian-manajemen-waktu.html

Moeloeng. (2004). Teknik Analisis Data dalam penelitian. UTCbWed, 27 Feb 2008

Nani, Sunarni. (2008). Drama Sebuah alternatif Obyek Penelitian Bahasa. Jurnal

Prayitno.(1995). Layanan Bimbingan dan Konseling kelompok ( Dasar dan Profil). Jakarta: Ghalia Indonesia.

Prayitno. (1997). Buku III Pelayanan Bimbingan dan Konseling Sekolah Menengah Umum (SMU). Jakarta: PT Bina Sumber Daya MIPA

Sudarsono. (1997). Kamus Psikologi. Jakarta: Rineka Cipta.

Trianto. (2011). Panduan Lengkap Penelitian Tindakan Kelas. Jakarta: Prestasi Pustakaraya.

Wikipedia (2019, 9 Juni). Waktu. Dikutip 6 Agustus 2019 dari Wikipedia: https://id.wikipedia.org/wiki/Waktu

Zaenudin . (2009). Pelayanan Konseling Dalam KTSP. Jakarta : P4TK

Zaenudin. (2009). Penelitian Tindakan Kelas Dalam Pelayanan Konseling. Jakarta : P4TK. 